\title{
Job satisfaction theories: Traceability to employee performance in organizations
}

\author{
${ }^{1}$ Stephen I. Dugguh, Ph. D, ${ }^{2}$ Ayaga, Dennis, Ph. D \\ ${ }^{I}$ Director, Centre for Entrepreneurship and Service Learning, Federal University, Kashere, Gombe \\ ${ }^{2}$ Department of Business Management, Benue State University, Makurdi
}

\begin{abstract}
Job satisfaction and employee performance has been a topic of research for decades. Whether job satisfaction influences employee satisfaction in organizations remains a crucial issue to managers and psychologists. That is where the problem lies. Therefore, the objective of this paper is to trace the relationship between job satisfaction and employee performance in organizations with particular reference to Nigeria. Related literature on the some theories of job satisfaction such as affective events, two-factor, equity and job characteristics was reviewed and findings from these theories indicate that a number of factors like achievement, recognition, responsibility, pay, work conditions and so on, have positive influence on employee performance in organizations. The paper adds to the theoretical debate on whether job satisfaction impacts positively on employee performance. It concludes that though the concept of job satisfaction is complex, using appropriate variables and mechanisms can go a long way in enhancing employee performance. It recommends that managers should use those factors that impact employee performance to make them happy, better their well being and the environment. It further specifies appropriate mechanisms using a theoretical approach to support empirical approaches which often lack clarity as to why the variables are related.
\end{abstract}

Keywords: Job satisfaction, employee performance, traceability, organizations, Nigeria

\section{Introduction}

It is no longer news that job satisfaction anchors employee performance. One of the most important goals of an organization is to maximize employee performance in order to accomplish those goals (Butler \& Rose 2011). In doing this, the organization needs not only highly motivated but also satisfied and psychologically balanced employees to increase performance and productivity in the organization. Employee satisfaction, performance and retention have always been very important issues in employee management literature and among human resource management practitioners especially in developing countries like Nigeria.

Good job analysis and job design, recruitment and selection exercise, training and development and other human resource activities play important roles in managing humans but few practices (and few organizations) have made job satisfaction a top priority in motivating employees to performance. This is perhaps because they have failed to understand the significant opportunity that lies at their disposal when they apply job satisfaction theories in their organizations. It is no gain in saying that satisfied employees tend to be more committed, creative, and more productive to their organizations. Recent empirical studies also indicate a direct correlation between job satisfaction and employee performance in organizations. Organizations that can create work environment that attract, motivate and retain hard-working individuals will be better positioned to succeed in a competitive national and global environment that demands quality and cost-efficiency.

Job satisfaction therefore 'is a pleasurable or positive emotional state resulting from the appraisal of one's job or job experiences' (Lock, 1976.130). While employee performance refers to the behaviours individuals engage themselves in or produce that are in line with and contribute to an organization's goal (Viswesvaran \& Ones, 2000). It is against this background that this paper aims at examining job satisfaction theories and how they affect employee performance in the organization with reference to the Nigerian business environment.

\section{Literature Underpinning}

A number of features: attitudes towards pay, working conditions, co-workers and managers, career prospects and intrinsic aspects of the job may influence the level of employee's satisfaction in the organization. Job satisfaction therefore is a measurement of job and work expectations and not just an overall holistic attitudinal manifestation. The concept of job satisfaction is multifaceted hence a number of theories are advanced to explain what it means and how the theories could be applied to enhance employee performance. Griffin \& Bateman (1986) and Hackman \& Oldman (1979) suggest that job satisfaction may be regarded as: a cluster of positive and negative dispositions which are acquired and learned through experience, positive or negative attitudes based upon a person's genetic inheritance, an outcome of an individual's construction of his or her workplace reality, experience and mutuality of colleagues and supervisor's evaluation, and an 
individual's job characteristics and the extent to which an individual attempts to fit in with these characteristics according to his requirements from a job.

\subsection{Job satisfaction theories traceable to employee performance}

As earlier stated, job satisfaction at its most general conceptualization, is simply how content an individual is with his job. Simply stated, job satisfaction refers to the attributes and feelings people have about their work. Positive and favourable attitudes towards the job indicate job satisfaction. Negative and unfavourable attitudes towards the job indicate job dissatisfaction Armstrong (2003). This satisfaction may be affective: one-dimensional subjective construct representing an overall emotional feeling individuals have about their job as a whole Kalleberg (1977) and Moorman (1993).

It may also be cognitive: more objective or logical evaluation of various facets of a job. Cognitive job satisfaction does not assess the degree of pleasure or happiness that arises from specific job facets, but rather gauges the extent to which those job facets are judged by the job holder to be satisfactory in comparison with objectives they themselves set or with other jobs. The two constructs are distinct, not directly related, have different antecedents and consequences though cognitive job satisfaction might help to bring about affective job satisfaction in the organization. The following job satisfaction theories that are easily traceable to employee performance in the organization are hereby listed and examined:

\subsubsection{Two-factor theory}

Among the content theories of motivation, Herzberg (1959) theory emphasizing the motivator-hygiene factors sought to explain satisfaction and motivation in the organization. The theory focuses on outcomes of satisfaction and dissatisfaction. The theory further found that certain aspects of a job cause satisfaction and therefore motivation, but certain aspects caused job dissatisfaction. Herzberg explained that the factors that lead to satisfaction or to dissatisfaction are different. Accordingly, he states that 'the opposite of job satisfaction is not job dissatisfaction but, rather, no satisfaction; and the opposite of job dissatisfaction is not job satisfaction but no satisfaction' (Herzberg, 2003.91). This theory states that job satisfaction and dissatisfaction is a product of different factors - motivation and hygiene respectively. Motivation is seen as an inner force that drives individuals to attain personal and organizational goals. Motivational factors are those aspects of the job that make people want to perform and provide people with satisfaction. Hygiene factors include aspects of the working environment like working conditions, interpersonal matters, organizational policies and so on (Hackman \& Oldham, 1976). Factors that relate to job satisfaction are therefore called satisfiers or motivators. According to Weir (1976) and Syptak, Marsland \& Ulmer (1999), the following factors stood out as 'strong determinants of job satisfaction'.

Achievement: This requires helping and placing employees in position that use their talents and not to set up for failure. It is achieved by setting clear, achievable goals and standards for each position, and making sure employees know what those goals and strategies are. Individuals should also receive regular, timely feedback on how they are doing and feel they are adequately challenged in their jobs.

Recognition: Refers to the honour, favourable note or attention given to an employee for a 'job well done' or an outstanding behaviour. Individuals at all levels in the organization want to be recognized for their achievement on the job. The individual's success does not have to be monumental before they deserve recognition. Employees should be acknowledged for doing something well immediately after their good work. Publicly appreciating them for finding solutions to a problem, writing a note of praise, establishing a formal recognition program like 'employee of the month or year', making periodic reports directly available to the employees themselves rather than to management, are some of the ways of recognizing employees.

Work itself: This involves helping employees believe that the task they are doing is important and meaningful. Setting goals and reminding and emphasizing that their efforts lead to and contribute to positive outcomes and goal accomplishment is crucial. Success stories and cases should be shared on how an employee's actions made a real difference in the organization. Also show employees how their work is essential to the overall processes that make the practice succeed. Unnecessary tasks can be eliminated or streamlined to bring about greater efficiency in the organization.

Responsibility: Responsibility is taken action for ones actions. Granting additional authority to employees in their activity, giving them enough job freedom and power so that they feel they 'own' the results are ways of giving them responsibility. As employees grow, they can be provided opportunities for added responsibility by adding challenging and meaningful work.

Opportunity for advancement or promotion: This involves electing employees from the present job or position to a higher one or level in the organization. If possible permit and support them to acquire higher certificates so that they could become experts themselves and make them more valuable to the practice and more fulfilled individuals.

Factors that relate to job dissatisfaction (dissatisfiers or hygiene factors) as explained by Herzberg are: 
Pay (salary): Organizations, they say, 'pay get what they pay for'. Salary is a contractual agreement between the employer and the employee. It not a motivator for them but do want to be paid fairly and when due. If an employee perceives that he is not fairly compensated, he will not be happy and so slow the pace of performance. Comparable salaries and benefits, clear policies relating to salaries, increments, bonuses and benefits must be clearly indicated to avoid dissatisfaction.

Supervision: This involves technical and general supervision in the organization. Wise decisions should be taken when it comes to appointing someone to the role of supervising. This role is difficult and requires good leadership skills and the ability to treat all employees fairly. There should also be positive feedback and a set means of evaluating or appraising employees.

Working conditions: The environment under which employees work has a tremendous effect on their level of pride for themselves and for the work they do. The provision of modern equipment and facilities, quality furniture, well ventilated offices, well spaced offices, secured, well spaced staff quarters, and so on are some of the conditions that are required to prevent job dissatisfaction in the organization.

Company policies, administration and procedures: An organization's policies, administration and procedures can be a great source of frustration for employees if the policies and procedures are unclear or unnecessary or if those to follow are selected. A policy permits an employee to use his discretion and initiatives in the discharge of his duties. Policies may not make employees satisfied and motivated but it can decrease dissatisfaction by making policies fair and applicable to all. Policy issues should be documented (manual) and distributed to employees, their inputs should be solicited for while comparing policies to those of similar practices. Policies should also be reviewed from time to time. Helping employees to use their initiatives can also go a long way in preventing dissatisfaction.

Interpersonal relationships: Relating well with peers, managers and subordinates encourages job dissatisfaction. Part of the satisfaction in employment contract is the social contact it brings to employees. Reasonable time should be given for socializing. This will help to develop a sense of teamwork and at the same time cracking down on rudeness, difficult behaviour and offensive comments. People should be encouraged to live in harmony irrespective of cultural and other diversities.

Status: This is a person's social rank in a group, which often is determined by a person's characteristics, in addition to the person's formal position. When status differ, it may be difficult to communicate effectively in the organization. To reduce dissatisfaction, managers should use both verbal and nonverbal forms of communications to pass messages to employees with the highest level of probability that the information circulated will be intact. The issue of status should also be diluted to avoid a situation whereby those with higher status will not influence members having lower status. Individual status should not be a yard stick for motivation.

Security: Security in this case refers to job security - freedom from threats of layoffs, frequent queries, harassment, discrimination, bullying and so on. When there is no job security, an employee's needs for higher growth will be blocked. If he works hard but security does not return, he will seek to fulfil his needs elsewhere or burn out. While motivators are part of the job content and relate to what people actually do in their work hygiene or dissatisfies are often associated with job context: associated more to the work setting than the nature of work itself.

\section{1.2. Affective Event Theory}

According to Thompson \& Phua (2001) the affective event theory was developed by Psychologist Howard M. Weiss and Russell Cropanzano to explain how emotions and moods influence job satisfaction. The theory explains the linkages between employees' internal influences - cognitions, emotions, mental states etc and their reactions to incidents that occur in their work environment that affect their performance, organizational commitment, and job satisfaction (Wegge, van Dick, Fisher, West \& Dawson, 2006). The theory further proposes that affective work behaviours are explained by employee mood and emotions, while cognitive-based behaviours are the best predictors of job satisfaction. In addition, the affective events theory emphasized that positive-inducing and negative-inducing emotional incidents at work are distinguishable and have a significant psychological impact upon workers' job satisfaction. This resulted in lasting internal and external affective reactions exhibited through job performance, job satisfaction and organizational commitment.

Rolland \& De Fruyt (2003) research findings on personality in support of affective events theory shows that there are a number of factors that influence the theory. These are: consciousness, agreeableness, neuroticism, openness to experience, and extraversion. Finally performance feedback has an important influence on employee affect. Regular reviews should be done on regular basis in both medium and large organizations. The type of feedback on performance provided by managers can affect employee performance and job satisfaction (Fisher \& Ashkanasy, 2000).

Closely related to this theory is Locke's (1976) Range of Affect Theory. The major premise of this theory is that satisfaction is determined by a discrepancy between what an employee wants in a job what he has 
in a job. The theory further states that how much one valued a given facet of work (for example, the degree of autonomy) moderates how satisfied or dissatisfied one becomes when expectations are or not met. When an employee values a particular facet of a job, his satisfaction is more greatly impacted both positively (when expectations are met) negatively (when expectations are not met), compared to one who does not value that facet. However, too much of a particular facet will produce stronger feelings of dissatisfaction the more a worker values that facet (Spector, 1997).

\subsubsection{Equity theory}

Equity theory, as reviewed by Walster, Berscheid \& Walster (1973) shows how a person perceives fairness in regard to social relationships. The theory presupposes that during a social exchange, a person identifies the amount of input gained from a relationship compared to the output, as well as how much effort another person's puts forth. Based on Adam (1965) theory, Huseman, Hatfield \& Miles (1987) further suggest that if an employee thinks there is an inequity between two social groups or individuals, the employee is likely to be distressed or dissatisfied because the input and the output are not equal. Inputs encompass the quality and quantity of the employee's contributions to his or her work. Examples of inputs include: time, effort, hard work, commitment, ability, adaptability, flexibility, tolerance, determination, enthusiasm, personal sacrifice, trust in superiors, support from co-workers and colleagues and skills. Output (outcomes) on the other hand is the positive and negative consequences that an individual (employee) perceives a participant has incurred as a consequence of his relationship with another. Examples of outputs include job security, esteem, salary, employee benefits, expenses, recognition, reputation, responsibilities, and sense of achievement, praise, thanks, and stimuli and so on.

The major concern in equity theory is about payment and therefore the cause of concern of equity or inequity in most cases in organizations. In any position in the organization, an employee wants to feel that their contributions and work performance are being rewarded with their pay. If an employee feels underpaid, he would be dissatisfied and therefore becomes hostile towards the organization and co-workers which may ultimately result to lack of motivation and low performance. Equity is multidimensional in nature. For example, it does not depend on our input-to-output alone. It depends on people's comparison between own input-output ratio and the ratio of others. Since equity is all about perception, employees form perceptions on what constitute a fair (balance or trade) of inputs and outputs by comparing their situation with other 'referents' in the market place as they see it.

From this comparison, when they perceive that their inputs are fairly rewarded by outputs, then they are satisfied, happier and more motivated in their work. They are de-motivated to their job and the organization when they perceive that their ratio of inputs-outputs is less beneficial than the ratio enjoyed by referent others (Ball, 2014). According to Adams (1963), when a person becomes aware of inequity, it causes a reaction in them, potentially some form of tension that is 'proportional to the magnitude of inequity present'. It is because of this tension that an individual might react in a way that reduces the tension in him. Equity theory further identifies four mechanisms for job satisfaction (dissatisfaction) as follows:

a. Employees seek to maximize their outcomes (rewards minus outcomes).

b. Groups can maximize collective rewards by developing accepted systems for equitably apportioning rewards and costs among members. That is, systems of equity will evolve within groups, and members will attempt to induce other members to accept and adhere to these systems.

c. When employees find themselves participating in inequitable relationships, they become dissatisfied or distressed. The theory explains that in this situation, both the person who gets 'too much' and the person who gets 'too little' feel dissatisfied. The employee who gets too much may feel ashamed or guilt and the employee who gets too little may feel angry or humiliated.

d. Employees who perceive that they are in an inequitable relationship attempts to eliminate their dissatisfaction by restoring equity. This could be done by either by distorting inputs, outputs, or leaving the organization.

Thus the theory has wide-reaching implications for employee morale, efficiency, performance, productivity and turnover. It also shows why employees see themselves the way they are treated in terms of their surrounding environment, teams, systems, etc collectively and not in isolation and so they should be managed and treated accordingly. In addition, the totals of employee inputs-outputs must be measured including their personal values. Schultz \& Schultz (2010) further extended equity theory to include the behavioural responses patterns to situations of equity or inequity. These response patterns are: benevolent (satisfied when they are under paid compared with co-workers), equity sensitive (believe everyone should be fairly rewarded) and entitled (employees believe that everything they receive is their just due).

\subsubsection{Job characteristics theory.}


Job characteristic theory (Hackman \& Oldham 1976), Schermerhorn, Jr (1984), Hellriegel, Jackson \& Slocum (1999) and Dugguh (2008) propose a framework to study how particular job characteristics affect job outcomes and job satisfaction. The framework states that there are a number of core job characteristics that impact on job outcomes. These are: Skill Variety (the degree to which a job requires a variety of different activities in carrying out the work and involves the use of different skills and talents of the individual), Task Identity (the degree to which the job requires completion of a 'whole' and identifiable piece of work - that is, one that involves doing a job from beginning to end with a visible outcome), Task Significance (the degree to which the job has substantial impact on the lives or work of people in other departments in the organization or in the external environment), Job Autonomy (the degree to which the job gives the employee substantial freedom, independence, and discretion in scheduling the work and in determining the procedures to be used in carrying it out) and Job Feedback (the degree to which carrying out the work activities required by the job results in the individual obtaining direct and clear information on the results of his performance).

These core job characteristics impacts three critical psychological states - experienced meaningfulness, experienced responsibility for outcomes of the work and knowledge of actual results of the work activities which in turn influence work outcomes (job satisfaction, absenteeism, work motivation and so on). The theory also recognizes that the core characteristics do not affect all employees in the same way. They affect more those in growth-need strength, that is, the employee's desire to achieve a sense of psychological growth in his work. Based on the preceding, a Motivating Potential Score (MPS) - an index of how likely a job is to affect an employee's attitudes and behaviours - can be calculated using the formula:

$\mathrm{MPS}=\frac{\mathrm{SV}+\mathrm{TI}+\mathrm{TS}}{3} \times \mathrm{AU} \times \mathrm{FB}$

Where: MPS = Motivator Potential Score

SV = Skill Variety

TI = Task Identity

TS $=$ Task Significance

$\mathrm{AU}=$ Autonomy

$\mathrm{FB}=$ Feedback

The formula explains the statement by Steel (2012) that jobs which are high in motivating potential must be also high on at least one of the three factors (SV, TI, and TS) that lead to experienced meaningfulness, and also must be high on both autonomy (AU) and feedback (FB). Steel further states that if a job is high on MPS, the job characteristics theory assumes that motivation, performance and job satisfaction will be positively affected and the likelihood of negative outcomes (absenteeism and turnover) will be reduced.

\section{Factors that affect job satisfaction}

Job satisfaction is affected by environmental, individual and psychological factors. Factors that relate to the environment are: communication, employee recognition and so on Krayer \& Westbrook (1986) \& Weiss \& Cropanzano (1996), while those that relate to the individual are emotions, genetics and personality Cote \& Morgan (2002). Those that are psychological in nature include one's life, family, and community Wright \& Cropanzano, (2000). These factors are briefly explained below:

Communication is one of the most important factors in job satisfaction. Whether it is overload, underload and superior-subordinate type, communication is the most important aspects of an employee's work in modern organizations. The management of communication is crucial for progress on the job. Demands can be characterized as a communication load - the rate and complexity of communication inputs an individual must process in a particular time frame. Employees in the organization may experience communication overload or under-load. Communication overload occurs when 'an individual receives too many messages in a short time which can result in unprocessed information or when an individual faces more complex messages that are more difficult to process'. When more inputs exist than outputs, the individual perceives a condition of overload. In comparison, communication under-load occurs when messages or inputs are sent below the individual's ability to process them. Accordingly, if an individual does not receive enough input on the job or is unsuccessful in processing these inputs, the individual is more likely to become dissatisfied, aggravated, and unhappy with their work which may lead to low level of job satisfaction.

Superior-subordinate communication is also an important influence on job satisfaction in organizations. The way an employee perceives a supervisor's behaviour can positively or negatively influence job satisfaction. Communication behaviour such as facial expression, eye contact, vocal expressions, body movement and language and so on are crucial to superior-subordinate relationship. These nonverbal communication from the superior helps to increase interpersonal involvement with their subordinates impacting job satisfaction. At times nonverbal communication appears to be more impacting than the verbal content. A manager who uses nonverbal immediacy, friendliness and open communication lines is more likely to receive positive feedback and job 
satisfaction from a subordinate. However, a manager who is antisocial, unfriendly and unwilling to communicate will receive negative feedback and create low job satisfaction in their subordinates in the organization.

Studies also indicate that employees derive satisfaction from working with companies that are effective in human resource management best practice - employee recognition programs and to some extent, financial reward programs. Employee recognition should not be confined to praise, gifts and points but should extend to changing the organization culture in order to meet goals, initiatives and connecting employees to the organization's core values and beliefs. This is strategic and strategic employee recognition is seen as the most important program to improve employee retention, motivation and positively influence the financial situation.

Emotions and mood form part of the individual affective factor in job satisfaction. Weiss \& Cropanzano opined that moods tend to be longer lasting but often weaker states of uncertainty origin, while emotions are often more intense, short-lived and have a clear object or cause. Mood relates to overall job satisfaction. Positive or negative emotions also relate to overall job satisfaction Brief \& Robertson (1989) and Weiss, Nicholas \& Daus (1999). Emotion management requires that all of the conscious and unconscious efforts to increase maintain or decrease one or more components of an emotion must be used. Suppression of unpleasant emotions decreases job satisfaction and the amplification of pleasant emotions increases job satisfaction.

Research indicates that genetics also influence job satisfaction due to its role in intrinsic - achievement or challenge as opposed to extrinsic - environmental factors like working conditions. Further, personality is associated with job satisfaction. Research by Brief \& Weiss (2002) describes the role of negative affectivity and positive positivity. Negative affectivity is related strongly to the personality trait of neuroticism. Individuals who are high in negative affectivity are more prone to experience less job satisfaction. Positive affectivity is related to the personality of extraversion.

Therefore, those who are high in positive affectivity are more prone to be satisfied in their lives and jobs they do. Alienation and locus of control are two personality factors that are most related to job satisfaction. Employees who have an internal locus of control and feel less alienated are more likely to experience job satisfaction, job involvement and job commitment. A meta-analysis of 135 studies for example of job satisfaction found that there is a positive relationship between internal locus of control and job satisfaction (Schultz, Schultz \& Duane, 2010).

Certain aspects of one's life like work, family, community and so on as defined by the 'overall effectiveness of an individual's psychological functioning' also affect job satisfaction. The psychological wellbeing has three defining characteristics: it is a phenomenological event, it involves some emotional conditions and it refers to one's life as a whole. Wright \& Cropanzano stressed that it is a global evaluation. It plays an important role in determining job satisfaction in that if focuses on both job satisfaction and job performance. Other job satisfaction theories that are useful for research on job satisfaction are: Dispositional theory, Opponent process theory, and so on. However, these theories could form the basis for further research.

\section{Employee Performance}

Performance is a multi-dimensional construct. It may be defined as the record of an individual's accomplishment. Kane (1996) argues that performance is something that the person leaves behind and that exists apart from the purpose. Performance, apart from being an outcome, is about doing the work as well as being about the results achieved. Campbell (1990) believes that performance is behaviour. For this paper, performance is "both behaviour and results. This is because behaviours emanate from the performer and transform performance from abstraction to results. It implies that when managing the performance of teams or individuals both inputs and (behaviour) and outputs (results) need be considered.

Employee performance therefore is the job-related activities expected of an employee and how those activities were executed. Campbell, McHenry \& Wise (1990) stated that employee performance consists of observable behaviours that people do in their jobs that are relevant to the goals of the organization. Murphy (1989) emphasize that definitions of job employee performance should focus on behaviours rather than outcomes. However, Motowidlo, Borman \& Schmit (1997) say that rather than solely considering the behaviour themselves, the evaluative aspects of behaviour should be also be emphasized consistent with the dominant methods used to measure job performance - performance ratings. The factors that are used in performance ratings are varied but Campbell et al suggest that studies should look at the dimensions separately because the general factor cannot possibly represent the best fit when rating employee performance. Several measures have been developed to measure employee performance. Though the measures vary in terms of how carefully and distinctively they are conceptualized with respect to affective or cognitive job satisfaction and so on.

While some researchers may use the Brief Index of Affective Job Satisfaction (BIAJS) method others may prefer the Job Descriptive Index (JDI). BIAJS is a 4-item overtly affective measure of overall affective job satisfaction and measures items like: internal consistency, temporal stability, job level, job type and so on. JDI 
specifically measures cognitive job satisfaction such as: pay, promotion and promotion opportunities, coworkers, supervision, and the work itself (Smith, Kendall \& Hulin, 1969).

Other measures that may combine those mentioned above include quality of work (input), quantity of work (output), time management, punctuality, goal setting, cost reduction on materials, money, people, information and energy, interpersonal skills and compliance, absenteeism, morale and anxiety.

\section{Literature Findings}

An important literature finding for organizations to note is that job satisfaction has a relationship with employee satisfaction which is tenuous. This serves as a piece of information to managers, businessmen and researchers. It is further observed in the literature that meta-analysis found that the relationship between satisfaction and employee performance can be moderated by job complexity such that for high complexity jobs the correlation between satisfaction and performance is higher than for jobs of low to moderate complexity. The review also found that job satisfaction predicts absenteeism, suggesting that increasing job satisfaction and organizational commitment are potentially good strategies for reducing absenteeism and employee turnover. It should also be noted that the relationship between job satisfaction and employee performance is not straightforward as many factors are responsible and the notion that 'a happy worker is a productive worker' should not be regarded as a foundation of organizational decision-making.

\section{Job satisfaction and employee performance: Integration and discussion}

Job satisfaction plays a crucial role in terms of employee performance, and to some extent his well being and to the organizations in terms of its productivity, efficiency, employee relations, absenteeism and turnover. Since job satisfaction is a complex variable, it can be influenced by situational factors on the job as well as the dispositional characteristics of the individual. Research examining relationships between job satisfaction and employee satisfaction and the methodologies utilized has great variations. These methodologies range from established scales, self-report ratings to peer or supervisor ratings.

However, the idea that job satisfaction leads to better employee performance is widely captured. For example, Vroom (1964) had earlier found that the notion that employee performance is a natural product of satisfying the needs of employees in the organization. Organizations that able to make their employees happy will have more productive employees. The idea that a happy worker is a productive employee is inconclusive because empirical studies have produced a number of conflicting viewpoints on the relationship between job satisfaction and employee performance (Strauss, 1968). It was on this basis that some researchers opined that employee performance may lead to job satisfaction but not the reverse and so job satisfaction is nonsignificantly correlated with employee performance in organizations.

One common research finding is that job satisfaction influences employee performance and life satisfaction. This correlation is reciprocal - people who are satisfied with life tend to be satisfied with their job and people who are satisfied with their job tend to be satisfied with life. In the Nigerian context where the rate of unemployment is high and the poverty rate is also high, the primary concern for many employees is not job satisfaction for many but finding a job that 'pays a decent wage'. Many employees in Nigeria do not experience job satisfaction. This is because too many people are pursuing too few jobs openings. Organizations have therefore taken undue advantage of unemployment opportunities to exploit the cheap labour. The resultant effect is that those who are lucky to be employed hardly talk of job satisfaction. They are more concerned with getting a wage just enough to 'take them home'.

\section{Concluding Remarks}

Job satisfaction and the variables presented in this paper are indication of how complex the concept of job satisfaction and employee performance is. The paper unveils the factors (achievement, recognition, work itself, responsibility, opportunity for growth, pay, supervision, work conditions, company policies, interpersonal relationship, status, security and so on) that should be included in order to further investigate job satisfactionemployee performance relationship. Empirical testing will demand a large number of observations because of variables and the academic disciplines that are involved.

Since dissatisfaction may be a matter of time and temporary or transitional in nature, studies that tend to investigate the time-factor should be undertaken to analyze job satisfaction behaviours at points in time. This involves the conduct of a longitudinal research approaches to job satisfaction. Current researches also point to the fact that the area of personality and job satisfaction is not fully considered. The paper provides a large scale theoretical work on job satisfaction-employee performance relationship in organizations especially in the Nigerian business environment. This is a valuable contribution because it will help to specify the mechanism underlying a relationship that has received a great deal of empirical support, but lacks clarity as to why the variables are related. The traceability of job satisfaction to employee performance is therefore theoretically 
relevant in all organizations: small, medium or large and attempts to bring the complex influences and interactions between the individual and his environment.

\section{Recommendation}

Based on the preceding, organizations, irrespective of size should endeavour to consider the factors that are relevant to job satisfaction and employee performance. Such factors range from achievement through responsibility to security. Though poverty and unemployment rate in Nigeria is very high, organizations should strive to satisfy employee needs to enable them to perform effectively. Employees in Nigeria have multiple needs based on their individual, family, and cultural values. These needs depend on the current and desired economic, political, and social status, career aspirations, the need to balance career, family, education, community, religion and so on. Satisfying these needs will not only lead to job satisfaction but also to life satisfaction bearing in mind that to some extent, a satisfied employee is a happy citizen.

\section{References}

[1]. Adams, J. S. (1963). Toward an understanding of inequity, Journal of Abnormal and Social Psychology, 67,422-36

[2]. Armstrong, M (2003). A Handbook of Human Resource Management Practice, $9^{\text {th }}$ edition, London: Kogan Page.

[3]. Butler, M. \& Rose, E. (2011). Introduction to Organizational Behaviour, Edited London: Chartered Institute of Personnel \& Development

[4]. Brief A.P. \& Weiss, H.M. (2002). Organizational Behaviour: Affect in the workplace. Annual Review of Psychology, 53,279-307

[5]. Brief, A. P \& Robertson, L. (1996). Job attitude organization: An exploratory study. Journal of applied Social Psychology 19: 71724

[6]. Campbell, L., Simpson, J.A., Stewart, M. \& Manning, J. (2003) 'Putting Personality in Social Context: Extraversion, emergent leadership, and the availability of reward.

[7]. Cote, S. \& Mogan L. M. (2002). A longitudinal analysis of the association between emotion regulation, job satisfaction, and intentions to quit. Journal of Organizational Behaviour Vol. 23, 947-962.

[8]. Davar, S.C (1987). Relationship between job satisfaction and job performance: A metal- analysis. Indian journal of industrial Relations. Vol. 48 No 2

[9]. Dugguh S. I. (2008). Human resource management, Makurdi: Oracle Press Ltd.

[10]. Griffin, R.W \& Beteman, T.S. (1986). Job satisfaction and organization, Review of Industrial and Organizational Psychology, 15788 .

[11]. Herzberg, F. (1968). Work and the nature of man. St. Albans: Staples Press.

[12]. Herzberg, F. (2003). 'One more time: how do you motivate employee?', Harvard Business Review, 81, 56-96

[13]. Hackman, J. R \& Oldham, G.R (1976). 'Motivation through the design of work' Organizational Behaviour and human performance, 16: $250-279$.

[14]. Hellriengel, D.J, Jackson, S. \& Slocum Jr. (1999). Management, $8^{\text {th }}$ edition, Cincinnati, South-western College Publishing.

[15]. Houseman, R, Hatfield, J, \& Miles E. (1987) 'A new perspective on Equity Theory'. TheEquity Sensitivity Construct', Academy of Management Review. 12(2): 232234

[16]. Kalleberg, A.L (1977). 'Work Values and Job rewards-Theory of Job Satisfaction', American Sociological Review 42:124-143

[17]. Krayer, K. J. \& Westbrook, L. (1986). The relationship between communication load and job satisfaction. World Communication, 15: 85-99.

[18]. Locke, E. A (1976). 'The nature and causes of job satisfaction' in Dunette, M D. (ed)Handbook of Industrial and organisation psychology. Chicago: RanMc Nally

[19]. Moorman, R. H (1993). The influence of Cognitive and effective based Job satisfaction measures on the relationship between satisfaction and organizational citizenship behaviour'. Human Relations 6: 759-776.

[20]. Rolland, J.P. \& De Fruet, F (2003). 'The validity of FFM personality dimensions and maladaptive traits to predict negative affects at work: A six month prospective study in a military sample', European Journal of Personality 17:5101 5121.

[21]. Spector, P.E (1997). Job Satisfaction: Application, assessment, causes and consequences. Thousand Oaks, CA. SAGE.

[22]. Schultz, D.P, Schultz S. E. (2010). Psychology and Work today: An introduction to industrial and organisational psychology. 10 edition.

[23]. Upper Saddle River: NJ: Prentice Hall. Smith, P.C, Kendall, L.M \& Hulin, C.L (1969). The measurement of satisfaction in work and retirement, Chicago: Rand McNally.

[24]. Strauss, C. (1968). Workers: Attitude and Adjustments. California: Institute of Industrial Relations

[25]. Sypatak, M.J, Marsland, D.W. \&Ulmer, D (1999). Job satisfaction: Putting theory into practice: Fam Practice Management. 6(9), 26-30.

[26]. Thomson, E, R \& Phua, F. T. T (2012). 'A Brief Index of Affective Job satisfaction, Organisation Management $37(3)$ : 275-307.

[27]. Vroom, V. (1964). Work and Motivation. New York: John Wiley \& Sons.

[28]. Waster, E.E, Berscheid, G.A \& Waster, G. W (1973). 'New Dimensions in Equity Research' Journal of Personality and Social Psychology 151-176

[29]. Wegge, J. van Dick, R. Fisher, G.K, West, M.A \& Dawson, J.F (2006). 'A test of basic assumptions of Affective Events theory (AET) in Call Centre Work' British Journal of Management Behaviour 21(2):123.

[30]. Weir, M. (1966). Job Satisfaction Challenge and Response in Modern Britain, Glasgow Williams Collins

[31]. Weiss, H.M \& Cropanzano, R (1996). Affective events theory: a theoretical discussion of structure, causes, and consequences of affective experiences at work. Research in Organisational Behaviour 8: 1-74

[32]. Weiss, H.M, Nicholas, J.P \& Daus, C.S (1999). An examination of the effects of affective experiences and job beliefs on job satisfaction and variations in affective experiences over time. Organizational Behaviour and Human Decision Processes 18: 1-24

[33]. Wright, T.A \& Cropanzano, R (2000). Psychological well-being and job satisfaction as Predictors of job performance. Journal of occupational Health Psychology. 5(1) 84-94 